\title{
TRACKING FARM MANAGEMENT PRACTICES WITH REMOTE SENSING
}

\author{
JP. Stals ${ }^{\text {a }}$, S. Ferreira ${ }^{\text {a }}$ \\ ${ }^{\text {a } G e o T e r r a I m a g e ~ P t y ~ L t d, ~ S o u t h ~ A f r i c a ~-~ c o b u s . s t a l s @ g e o t e r r a i m a g e . c o m ~}$
}

KEY WORDS:_Crop estimates, crop frequency, crop rotation, farm management, centre pivot irrigation, South Africa, satellite

\begin{abstract}
:
Earth observation (EO) data is effective in monitoring agricultural cropping activity over large areas. An example of such an application is the GeoTerraImage crop type classification for the South African Crop Estimates Committee (CEC). The satellite based classification of crop types in South Africa provides a large scale, spatial and historical record of agricultural practices in the main crop growing areas. The results from these classifications provides data for the analysis of trends over time, in order to extract valuable information that can aid decision making in the agricultural sector. Crop cultivation practices change over time as farmers adapt to demand, exchange rate and new technology. Through the use of remote sensing, grain crop types have been identified at field level since 2008, providing a historical data set of cropping activity for the three most important grain producing provinces of Mpumalanga, Freestate and North West province in South Africa. This historical information allows the analysis of farm management practices to identify changes and trends in crop rotation and irrigation practices. Analysis of crop type classification over time highlighted practices such as: frequency of cultivation of the same crop on a field, intensified cultivation on centre pivot irrigated fields with double cropping of a winter grain followed by a summer grain in the same year and increasing cultivation of certain types of crops over time such as soyabeans. All these practices can be analysed in a quantitative spatial and temporal manner through the use of the remote sensing based crop type classifications.
\end{abstract}

\section{INTRODUCTION}

Agriculture has seen significant changes over the last 200 years, firstly with the advent of farm machinery and engines replacing human and animal power in farming with a resultant increase in production. Scientific developments have further increased crop production with the development of new crop varieties and better resilience of these varieties to climatic conditions, disease and insect damage. Other scientific developments in farming practices, soil quality measurement and management and irrigation and water usage has further contributed to optimising crop yields. In the last 20 years the advent of GPS technology has introduced a further revolution in farming. This technology enabled farmers to manage their fields based upon variabilities within the field, using the positioning properties of GPS in conjunction with farm machinery to guide management and decision making at a very fine level within each field and thus the Precision Agriculture movement was born. The increased use of land observing satellites and aerial photography within this period and more recently UAV's, is an essential part in the Precision Agriculture movement, with location based images enabling monitoring crop and field conditions to aid decision making.

Field level Precision Agriculture is not the only area in which satellite imagery and aerial photography can be useful in agriculture. At the district, regional and even national level especially, satellite imagery provides a valuable data source to monitor crop type and extent. Satellite derived data and analysis can aid many decision makers at this level in various sectors such as disaster monitoring, crop statistics agencies and agricultural economics organisations. GeoTerraImage (GTI) has played a leading role within South Africa by utilising satellite technology and providing solutions within agriculture. As an information contributor to the South African $\mathrm{CEC}^{1}$ in the form of crop area cultivated estimates for grain crops since 2008, GTI has built up considerable experience and methodologies in delivering reliable, timely and accurate information. This historical information of crop type cultivated at field level can now be analysed and new information and insights gained into farming practices at district and provincial level. The continuous advances in information technology and Earth Observation (EO) technology allows even more value adding for the agricultural sector with increased earth observation sensors and increased computing power.

The aim of this paper is to present 3 types of analyses which produce further insights into farm management practices, that were undertaken using satellite derived crop type information at district and provincial levels. 1.) The increase and decrease of certain crop types cultivated over time in a region can be calculated. 2.) The resolution of satellite imagery that is analysed allows one to determine the frequency of crops cultivated on a field over time. Thus one can determine if regular crop type rotations takes place or if one type of crop is preferred. This information is then summarised at district level. 3.) The increase and decrease of irrigated fields in the form of centre pivot irrigation in a region over time can be determined and therefore can provide valuable information as to water usage from underground or piped water sources. The occurrence of double cropping (when a winter and summer crop is cultivated in the same growing year on the same field, usually on irrigated fields) can also be determined and monitored using the same data. The

\footnotetext{
${ }^{1}$ Crop Estimates Committee
} 
aim is to summarise all this information into a useable format at district and provincial levels for use for organisations working at that level.

\section{History of satellite image classification}

Raster based satellite image processing techniques were used in conjunction with a very accurate stratification layer of mapped fields for the provinces in South Africa. All analysis of crops or potential crops were conducted within this mapped stratification layer of field boundaries. This layer is updated annually by on desktop mapping from satellite images. A large scale aerial campaign with agronomic experts and farmers are conducted annually in the early growing season to identify crop types cultivated. This campaign is conducted within a statistical framework to determine accurate estimates of area of crops cultivated for each province. The aerial campaign data is accurately geo located with on-board GPS devices on each plane and the crop type on a field identified with a low flight observation by the farmers or agronomists. These annual geolocated data points are used as training and verification data in satellite image classification. Classifications per province per year are selected according to the $\mathrm{DAFF}^{2} \mathrm{CEC}$ requirements, therefore classifications were not conducted for each province for each year. The additions of new satellite sensors such as Landsat 8 and Sentinel 2A increased the chances for cloud free summer growing season acquisitions and increases the potential for reliable and accurate crop type classifications annually. The most important and widespread summer crops are maize, soybeans and sunflower. Wheat in South Africa is planted in winter and harvested in spring and followed a separate classification procedure using winter and spring images. These are the crops which were analysed in this paper.

\section{Approach: Linking data for Analysis}

GTI uses the national South African field boundary dataset for calculating and reporting crop areas. Satellite raster based classifications are transferred into the field boundary vector dataset. These user mapped boundaries ensure a high level of accuracy when calculated crop areas are reported. The field boundaries dataset is updated annually from satellite imagery over the major grain producing regions of South Africa.

- The historic pixel raster based classifications were transferred into the most recent field boundary vector dataset table per province.

- Vector database table calculations were then used for analysis of the crop information per year. The Freestate and Mpumalanga provinces were analysed for the purpose of this study as they had the most recent and annual classifications available.

- Data was analysed in the Freestate for the 2010, 2014, 2015 and 2016 summer grain periods and for Mpumalanga the analysis were conducted for the period 2014-2016.

The purpose of the study was to determine regional trends. Therefore, all field boundaries were grouped into the province district in which they occur and the results were reported at district level. These results were also summarised to a district level for each province in order to display the results and conduct further analysis. Figure 1 below shows an example of a Sentinel 2A image over Mpumalanga with district boundaries overlaid. Figure 2 shows a visual example of the field boundaries classified to a crop type, with each different crop type as a unique colour.

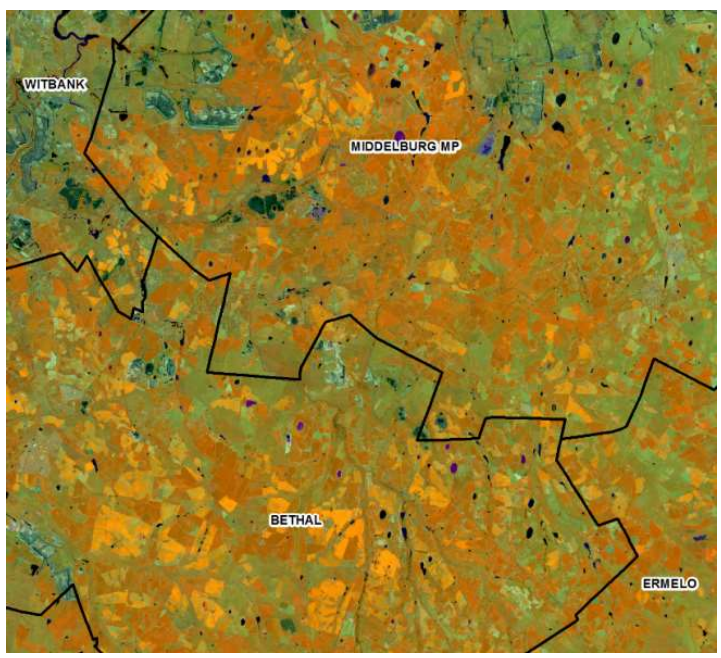

Figure 1. A Sentinel 2A image with Mpumalanga district borders overlaid

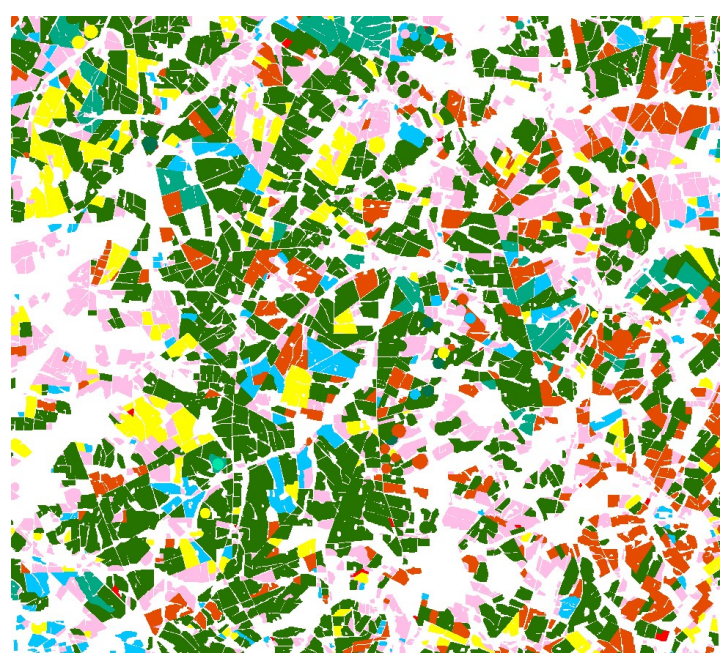

Figure 2. Field boundaries classified to different crop types represented by different colours

\section{Crop Area Change}

The summary of the field boundary vector classification per year at the district level enabled one to view the trend of crop preferences per district and also the change in area of each crop type per district. This analysis could highlight certain farm management decisions. For example the adoption of new crop types per district could be quantified by calculating increases and decreases in area of certain crop types within a district between

\footnotetext{
${ }^{2}$ Department of Agriculture Forestry and Fisheries (South Africa)
} 
time periods. The crop type area totals in hectares $(\mathrm{Ha})$ per district per year also enables one to see if there are any increasing preferences for certain types of crops. An example analysis was done between the years 2010 and 2014 for the Freestate. Figures 3-6 below displays the hectares cultivated in the Freestate for maize and soybeans per district for 2010 and 2014 as maps.

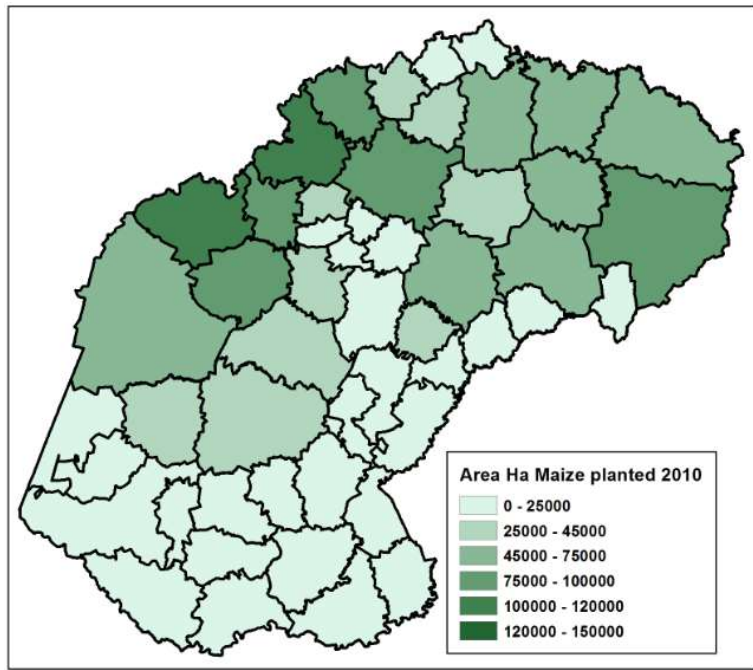

Figure 3. Calculated area in Ha for maize in 2010

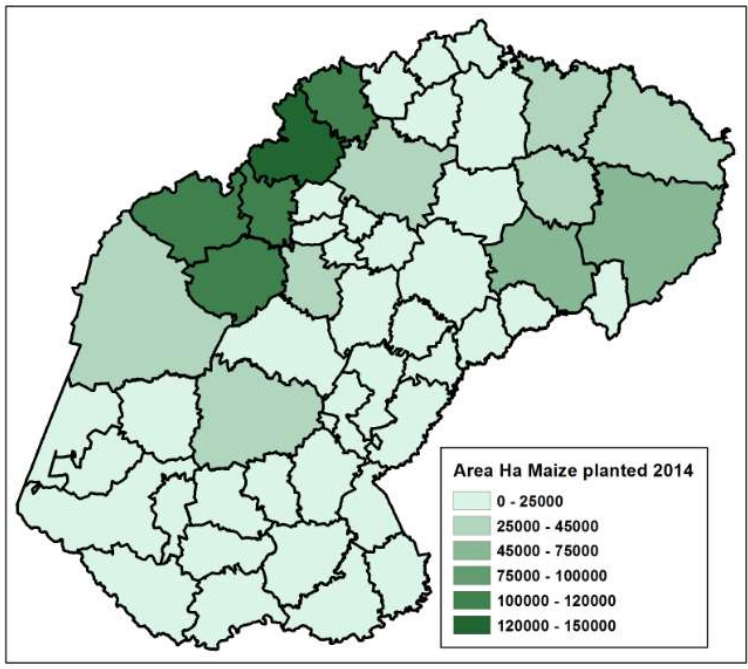

Figure 4. Calculated area in Ha for maize in 2014

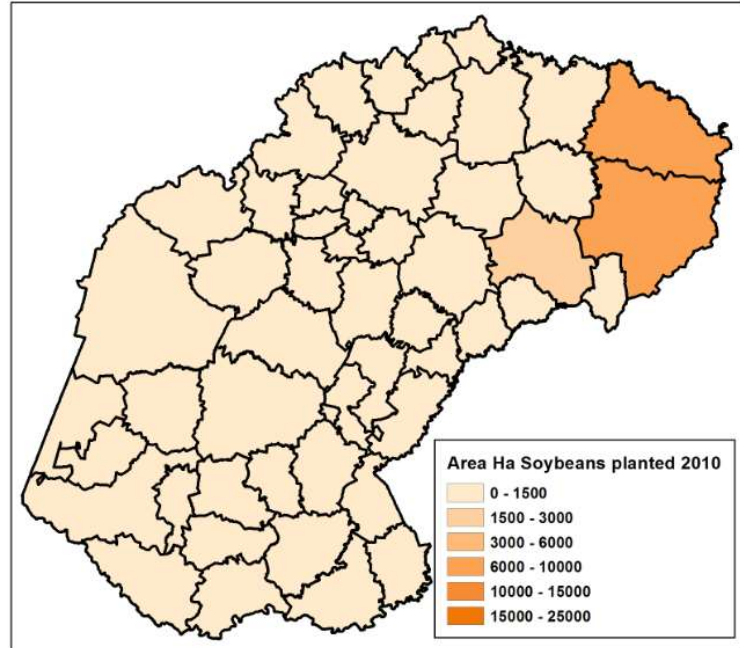

Figure 5. Calculated area in Ha for soybeans in 2010

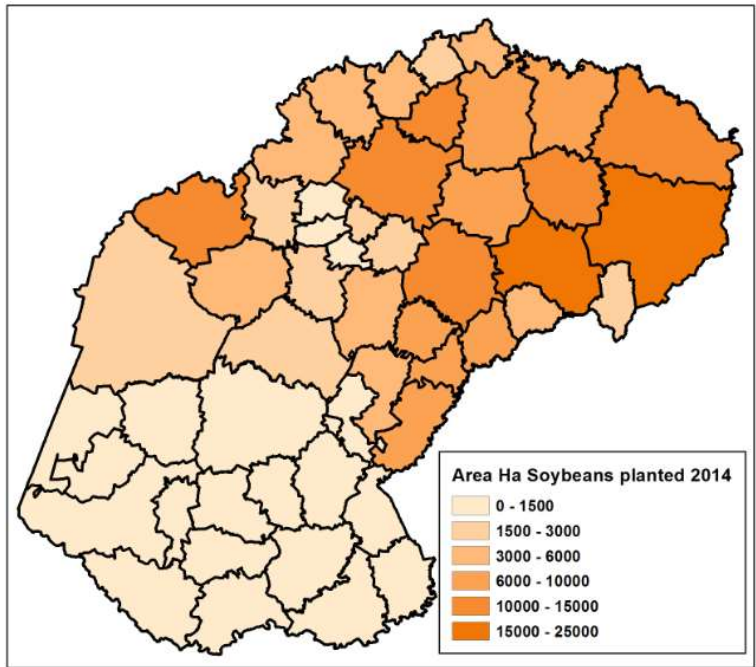

Figure 6. Calculated area in Ha for soybeans in 2014

The results of this analysis above shows the dominant role of maize in the Freestate. But examining the areas for soybeans in 2010 and 2014 it is possible to see a marked increase in soybeans in the eastern Freestate, and a few in selected districts in the west. The summarised crop type data per the district also enables one to calculate the percentage that each crop type represents in a district. This calculation was done on the main summer crops of maize, soybeans and sunflower expressed as the percentage of area of all these crops within the district. This calculation highlights the common crop type in the district and gives insights and further knowledge about management practices and preferences per district. From the area cultivated per crop, preferences for crops can be calculated. Figures 7-10 show the percentage calculated from the area (in $\mathrm{Ha}$ ) of the major crops (maize, soybeans, sunflower) of the maize and soybean crop cultivated for 2010 and 2014. 


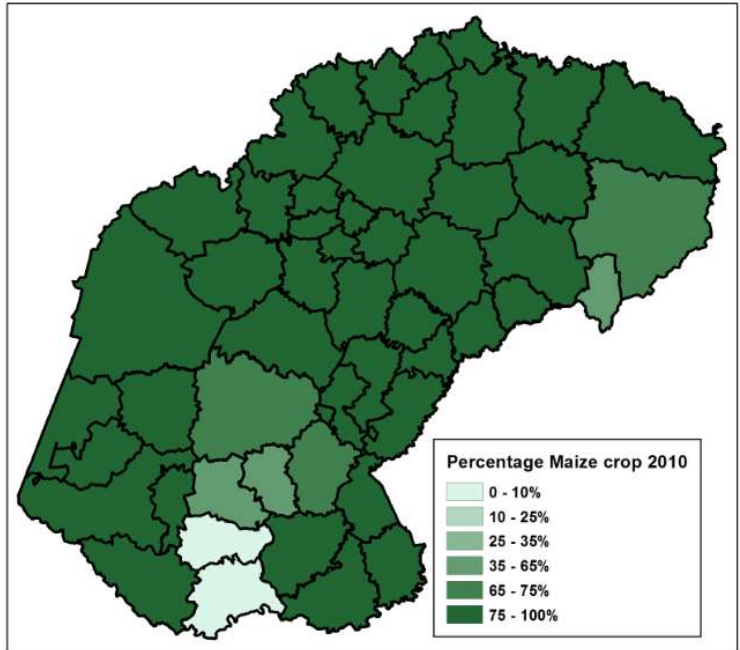

Figure 7. Calculated percentage of maize from other cultivated crops in 2010

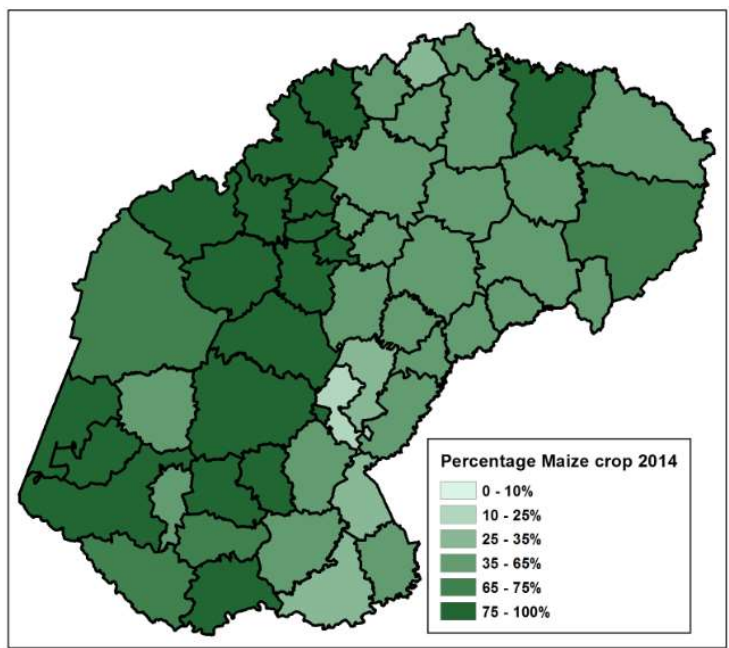

Figure 8. Calculated percentage of maize from other cultivated crops in 2014

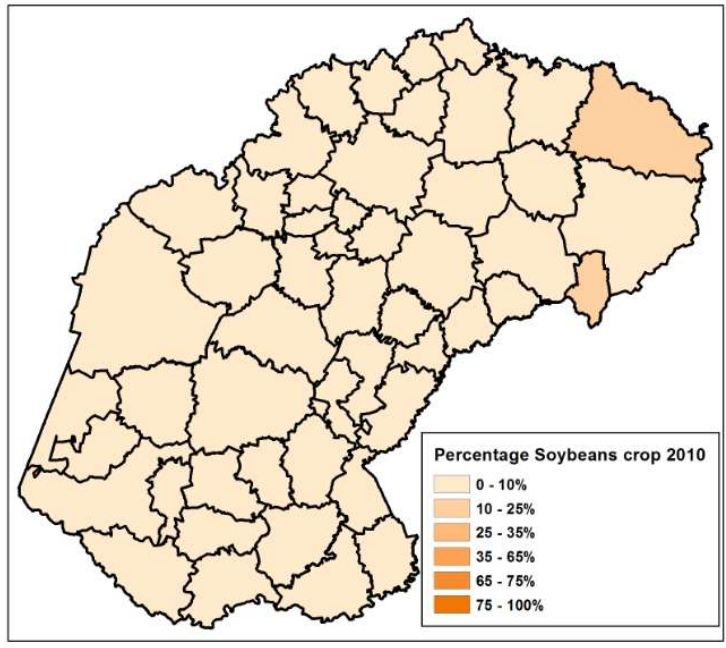

Figure 9. Calculated percentage of soybeans from other cultivated crops in 2010

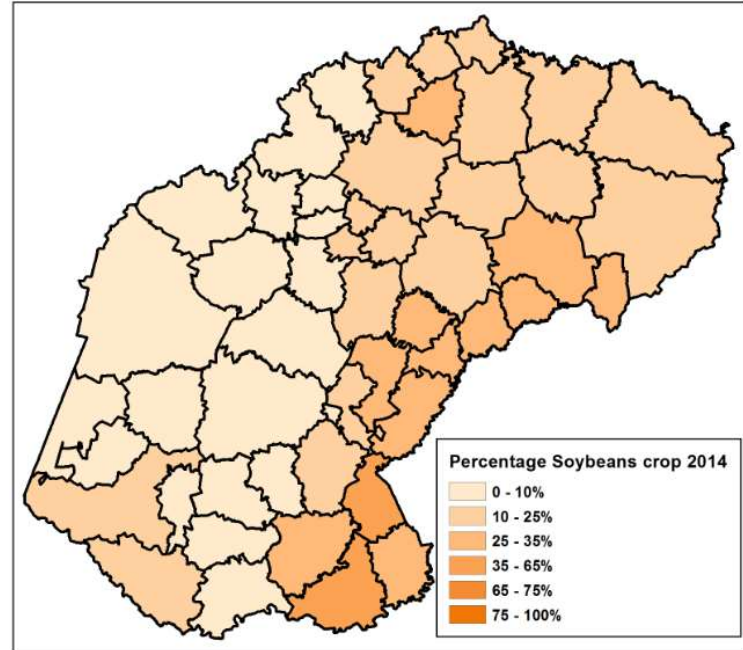

Figure 10. Calculated percentage of soybeans from other cultivated crops in 2014

From the figures above it is clear that the dominant preference for maize crops decreased from 2010 to 2014 in many districts, with a marked increase of the percentage of soybeans of all crops cultivated within this period, especially in the eastern regions. When Figures 7-10 are viewed in conjunction with one another, one can determine that soybeans has become a popular crop in the eastern Freestate between 2010 and 2014. The increase in hectares (Ha) of a crop type between periods could also be calculated per district. Figure. 11 below illustrates the increase in area of soybeans cultivated between 2010 and 2014 . The increase in area cultivated was most significant in the eastern districts which has a slightly cooler climate and generally higher above sea level than the west. However, the analysis shows large increases in the amount of soybeans cultivated between 2010 and 2014 are also recorded in some districts in the west

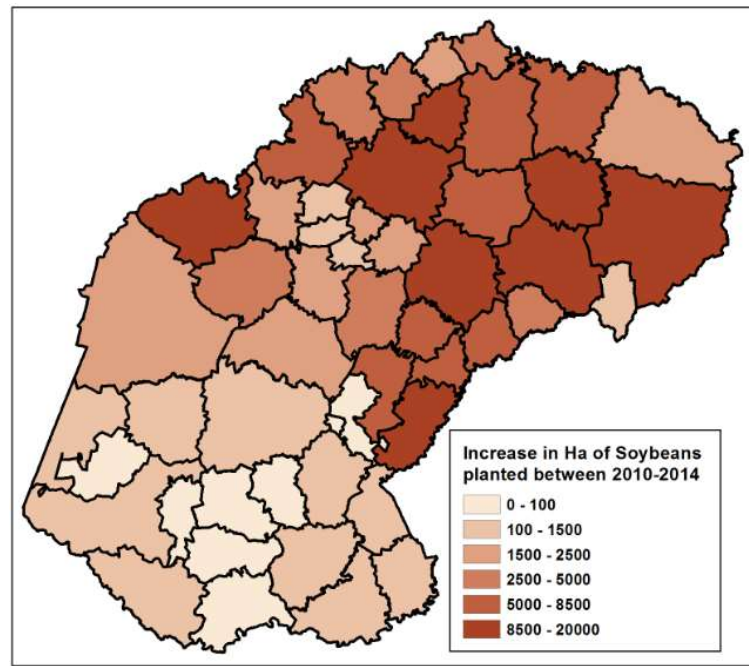

Figure 11. Calculated increase in area (Ha) of soybeans cultivated in 2010 and 2014

Following the process above, the increase and decrease per crop per district between years could be expressed in area hectares. The results of increase or decrease of maize in the Freestate between 2014-2015 and between 2015-2016 are displayed as maps in Figures 12-13. 


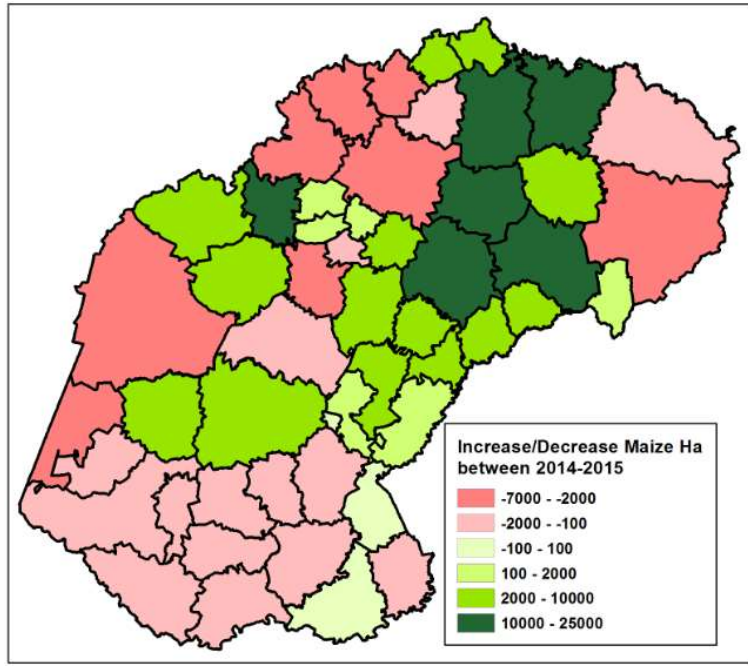

Figure 12. Calculated increase or decrease in area (Ha) of maize cultivated in 2014 and 2015 in Freestate

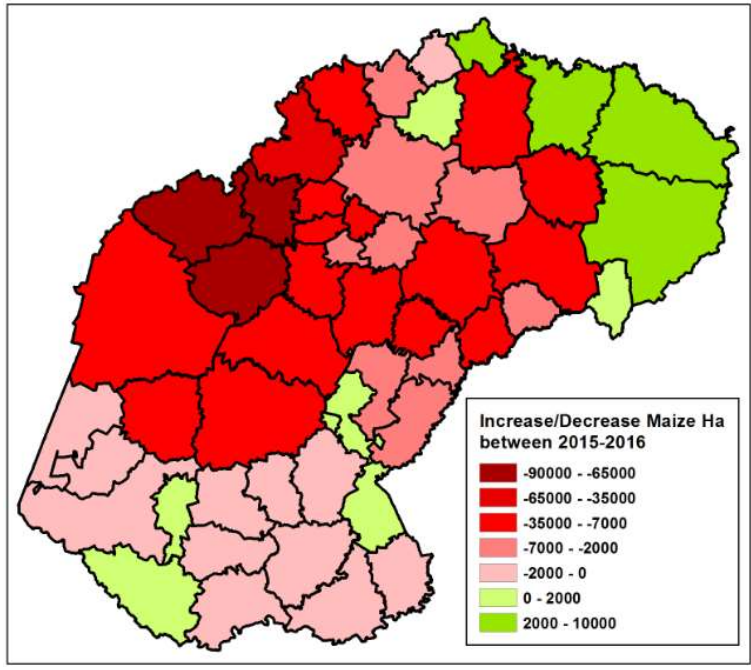

Figure 13. Calculated increase or decrease in area (Ha) of maize cultivated in 2015 and 2016 in Freestate

From the maps of maize increase or decrease Ha cultivated per district in the Freestate (Figures.12\&13) it is evident that between 2015 and 2016 a massive decrease in maize cultivated over most districts are observed. In 2016 South Africa faced a major drought which severely affected the Freestate province. The drought affected the western regions of the Freestate more than the eastern regions. The high maize producing districts on the north western border (refer to Figures 4\&8) showed massive decreases in the area cultivated with maize between 2015 and 2016. The CEC maize estimate dropped from $1220000 \mathrm{Ha}$ in 2015 to $700000 \mathrm{Ha}$ in 2016 (DAFF 2015 \& DAFF 2016). Soybean area change maps for the same periods are found in Figures $14 \& 15$.

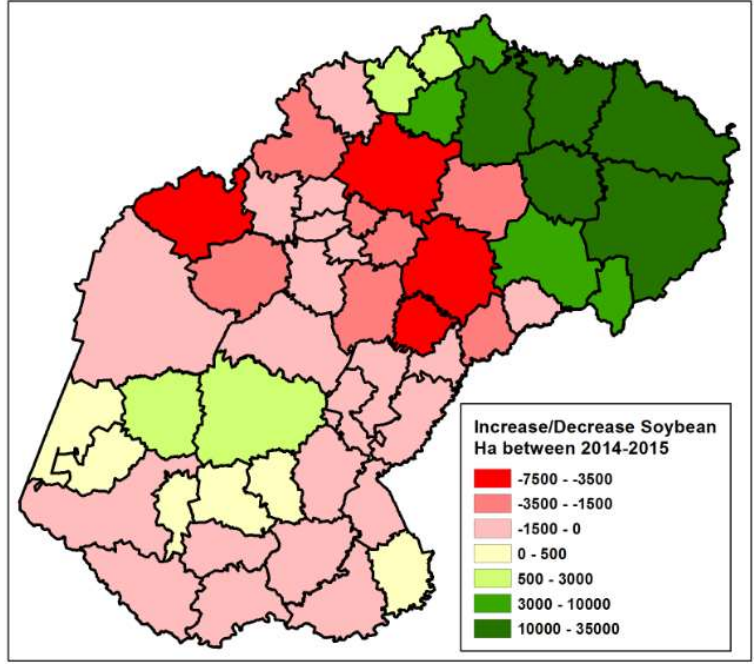

Figure 14. Calculated increase or decrease in area (Ha) of soybeans cultivated in 2014 and 2015 in Freestate

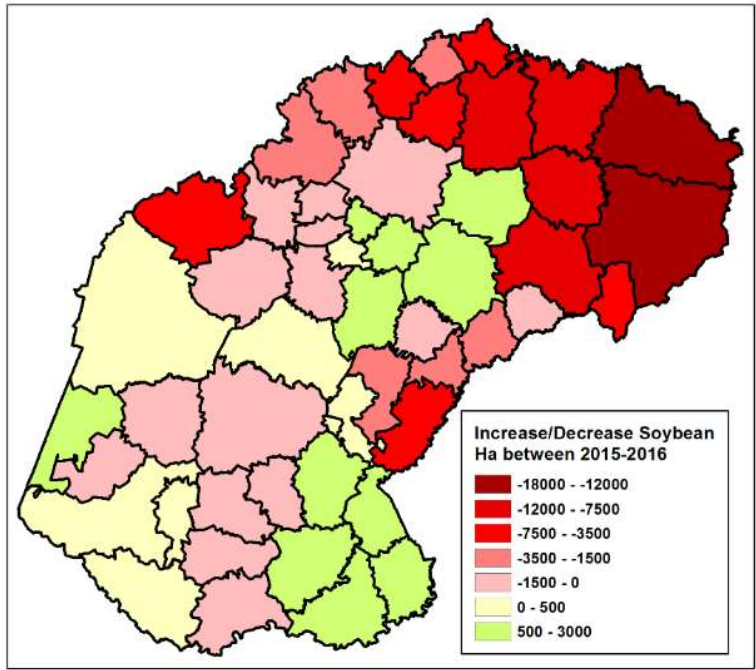

Figure 15. Calculated increase or decrease in area (Ha) of soybeans cultivated in 2015 and 2016 in Freestate

The change in soybeans cultivated per district in the Freestate also presents an interesting picture. Between 2014 and 2015 the greatest increase for a district was almost 35000 hectares. The highest reduction was only about $6000 \mathrm{Ha}$ in a district. Between 2015 and 2016 it is evident that the drought also affected the planting of soybeans. The CEC reported that in 2015 the Freestate cultivated approximately $305000 \mathrm{Ha}$ of soybeans, and in 2016 that figure was reduced to only $174000 \mathrm{Ha}$ (DAFF 2015 $\&$ 2016). From our district analysis it was calculated that in 2016 the district with the highest reduction of soybean area cultivated recorded a reduction of only about $18000 \mathrm{Ha}$. For maize in 2016 the district with the highest maize area reduction recorded an almost 90000 Ha reduction.

The same analysis of maize and soybeans was done for the Mpumalanga province. Mpumalanga province is located northeast of the Freestate and was less affected by the drought. The calculations for maize and soybean increase between 2014 2015 and 2015-2016 are shown in maps in Figures 16-19. 


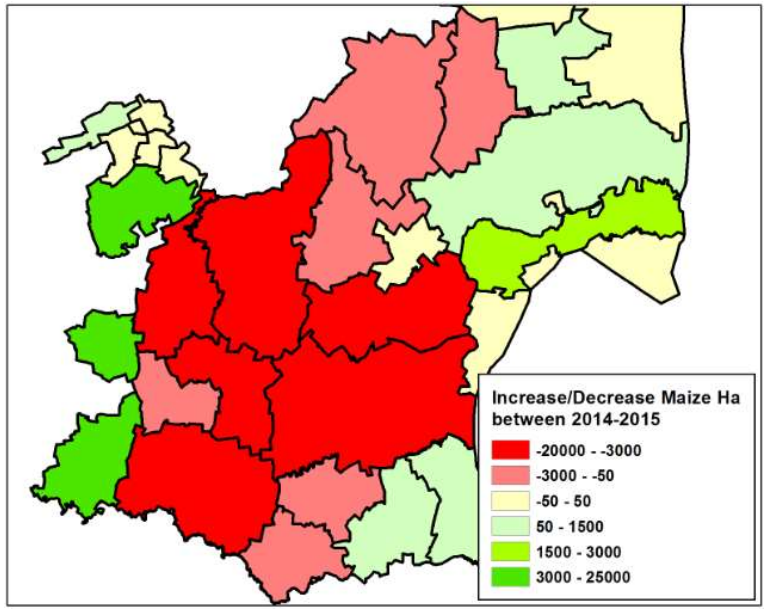

Figure 16. Calculated increase or decrease in area (Ha) of maize cultivated in 2014 and 2015 in Mpumalanga

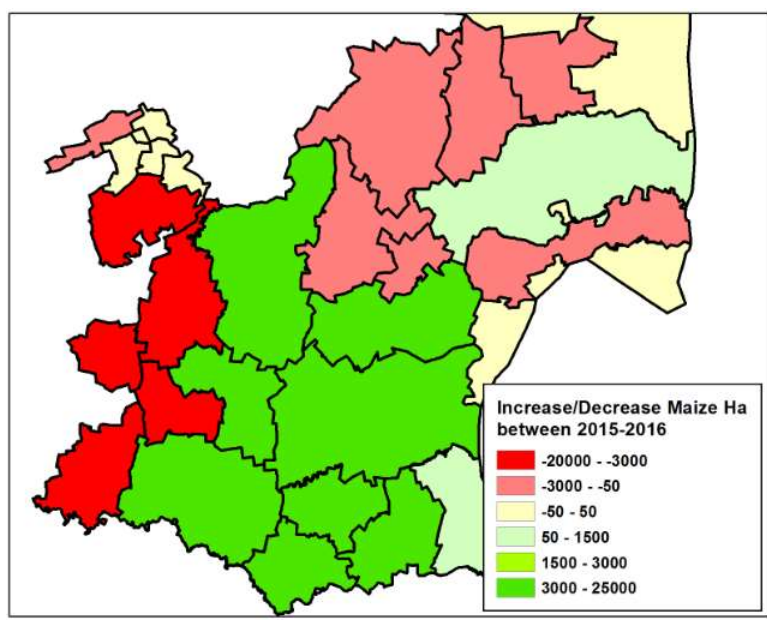

Figure 17. Calculated increase or decrease in area (Ha) of maize cultivated in 2015 and 2016 in Mpumalanga

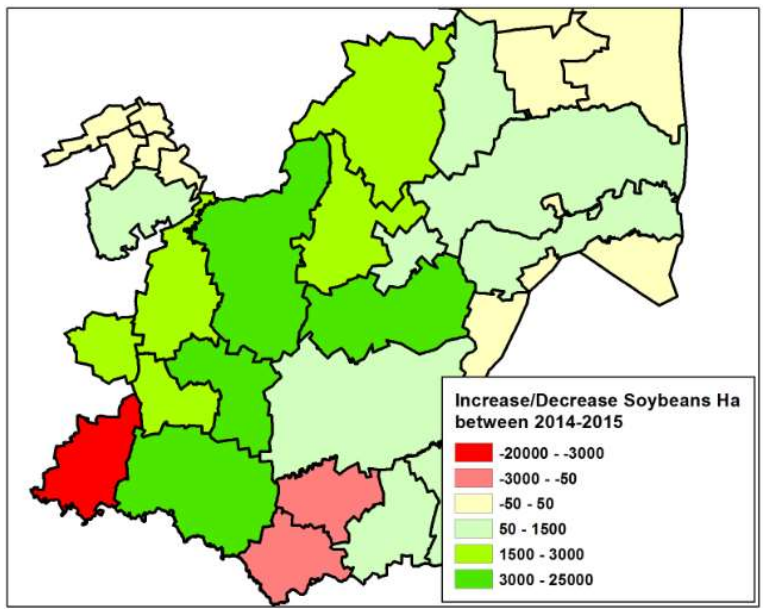

Figure 18. Calculated increase or decrease in area (Ha) of maize cultivated in 2014 and 2015 in Mpumalanga

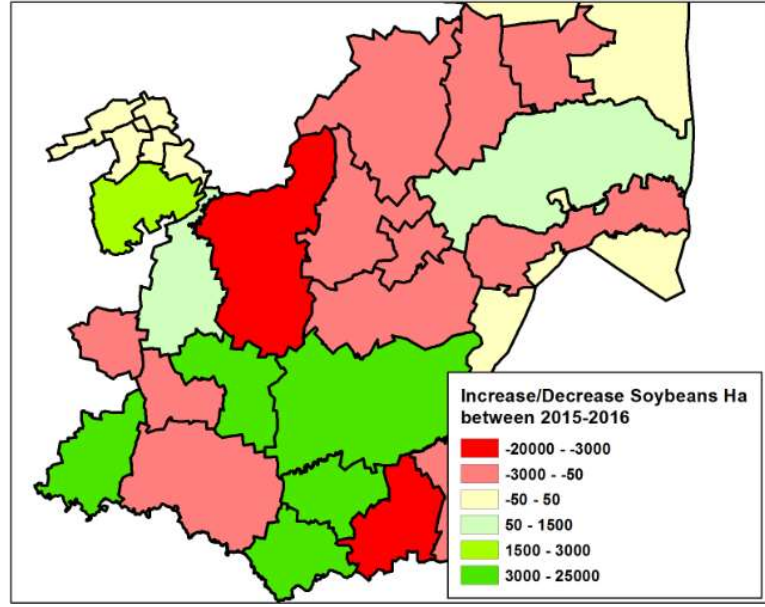

Figure 19. Calculated increase or decrease in area (Ha) of maize cultivated in 2015 and 2016 in Mpumalanga

An interesting pattern emerges in some districts when one views the Figures 16-19 above. There seems to be a reduction in maize area between 2014 to 2015 followed by an increase in maize area between 2015 to 2016 in these districts. The opposite was observed for soybeans where there was an increase in 2014 and 2015 followed by a reduction in soybean area between 2015 and 2016. The annual crop rotation between maize and soybeans is a common farming practice and may be a valid explanation for the trend observed in the maps. This thought is explored in the next section.

\section{Crop Frequency and Rotation}

The USDA $^{3}$ has developed methods to calculate crop frequencies over time using their annual Cropland Data Layer, a dataset similar to the South African crop type classification. Their work using crop frequencies were done to aid in developing frame stratifications in order to improve crop survey estimates (Boryan et al, 2017). A similar approach was followed using the annual crop type classifications for South Africa. Using the crop type classifications over multiple years enables one to calculate the frequency of crop occurrence over years per field. Spatial modelling of raster crop layers over consecutive years resulted in crop frequency layers per type of crop over a number of years. The crop frequency layers for different crop types could then be determined per field. A result of crop frequency over 3 years (2014-2016) for maize and soybeans in Mpumalanga is shown in Figure 20 and Figure 21. This same time period was also used to calculate frequencies for the Freestate province.

The frequency calculations per crop was used to calculate whether rotation between different crops in the time period took place. The frequency calculations could also be used to determine whether certain crop types are stable within an area and are cultivated year on year. The combination of frequency layers of different crop types enabled one to detect crop rotation of different crops. Therefore, a field which had one or more instance of crop A in the 3-year period and one or more instance of crop B in the 3-year period are considered to be rotated between crop A and crop B. This information was summarised at the district level and further analysis conducted at this level.

\footnotetext{
${ }^{3}$ United States Department of Agriculture
} 


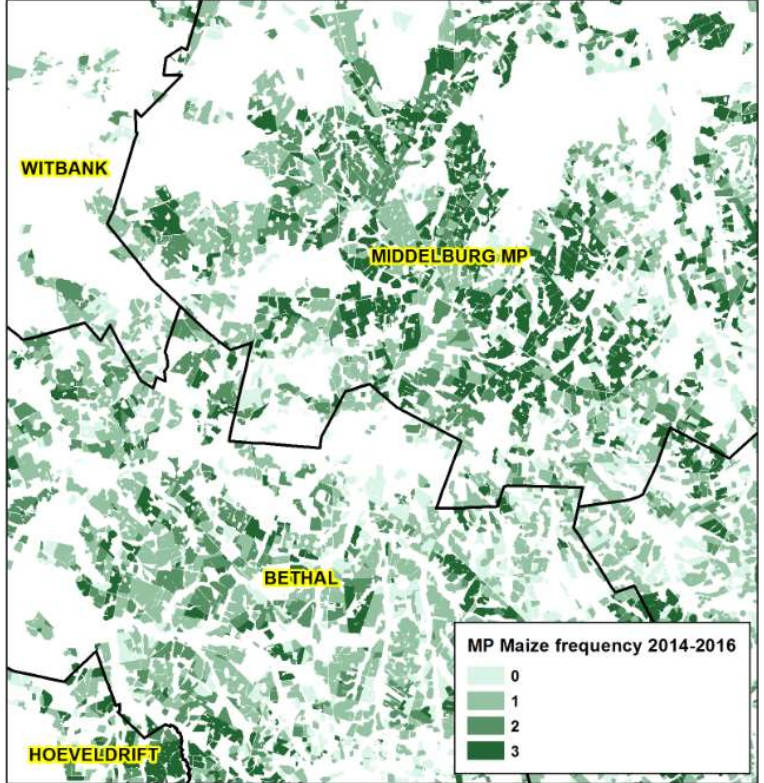

Figure 20. The frequency occurrence of maize per field between 2014 and 2016 in an area of Mpumalanga

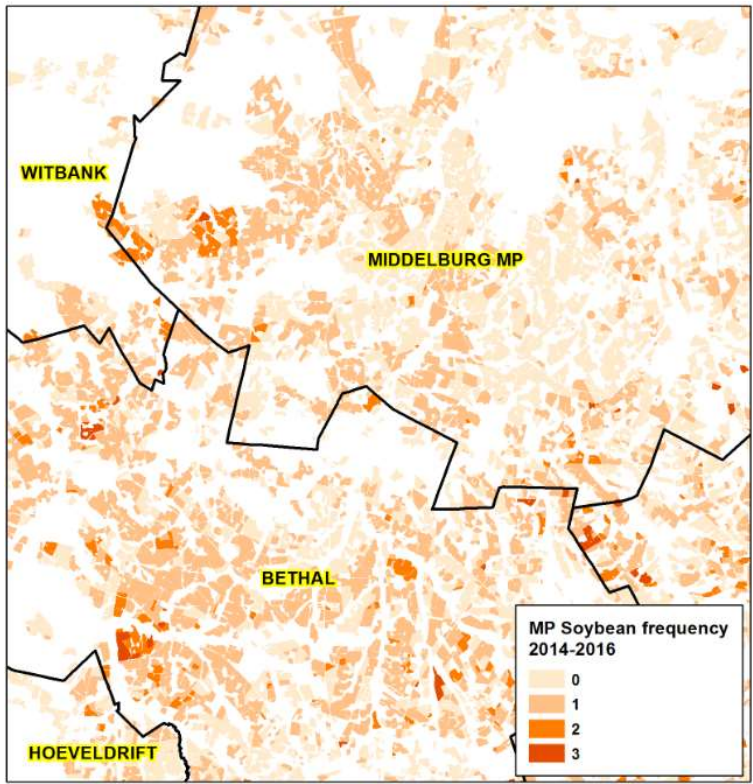

Figure 21. The frequency occurrence of soybeans per field between 2014 and 2016 in an area of Mpumalanga

At the district level the area of rotation between two specific crops could now be calculated. The area of rotation is expressed as the amount of area of two specific crops that were rotated. This rotated area was derived and summarised from each field in the previous step. In Mpumalanga maize and soybeans were regularly rotated on a field in many areas and was therefore used as an example for this analysis. The area of rotation in a district in the following examples are expressed between maize and soybeans. From this analysis the percentage of the rotated area of these two crops were calculated. This percentage is expressed as the percentage of the area of rotation of the total area for both crops in the district at the final year of analysis (2016 in this case). Taking the total area of crops rotated for maize and soybeans and also the percentage rotated from 2014 to 2016 summer growing season, the information is displayed at the district level. Figure 22 displays the area of rotation between maize and soybeans for the Bethal and Middelburg districts in Mpumalanga. Figure 23 displays the percentage of area of maize and soybeans that are rotated calculated from the frequencies.

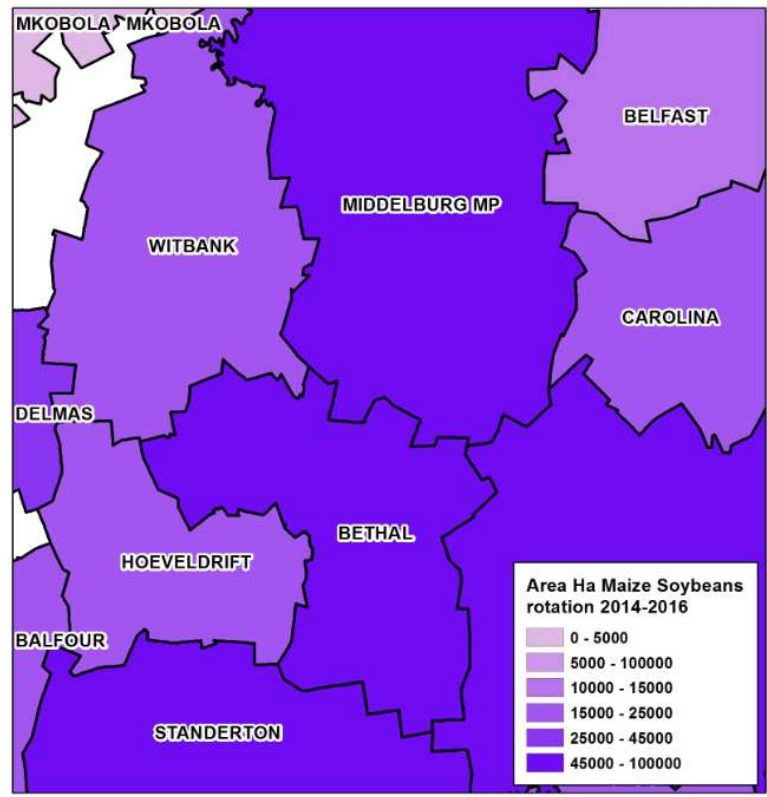

Figure 22. Area Ha of maize and soybeans which were rotated between 2014 and 2016

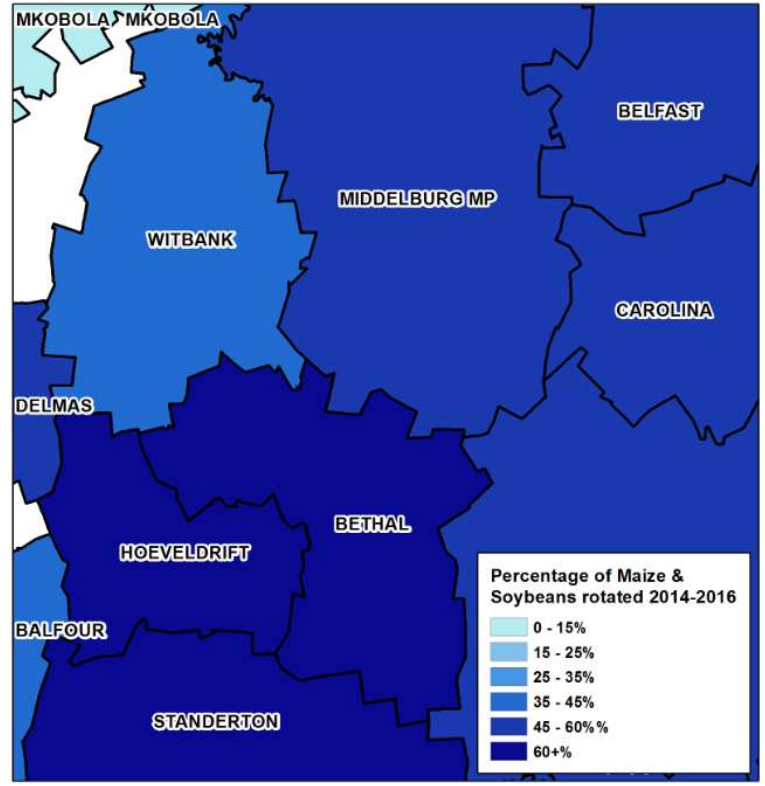

Figure 23. The percentage of the area of maize and soybeans which were rotated between 2014 and 2016

It is clear that certain districts have a larger total area of crop rotation and a larger percentage area of crop rotation than other districts. Viewing Bethal and Middelburg in the Figure 22 above one can see that they have a similar amount of area being rotated between maize and soybeans. But in Figure 23 the percentage of 
the maize and soybean area being rotated for the district is displayed. It is clear that the percentage of the crops under rotation practice is significantly higher in Bethal than Middelburg. This can allude to the farming practices and preferences of farmers have between the two districts. In the Freestate differences between the two districts of Reitz and Viljoenskroon for maize and soybean rotation from 2014 to 2016 is even more apparent as shown below in Figures $24 \& 26$ for the area of rotation and Figures $25 \& 27$ for the percentage of the area of rotation

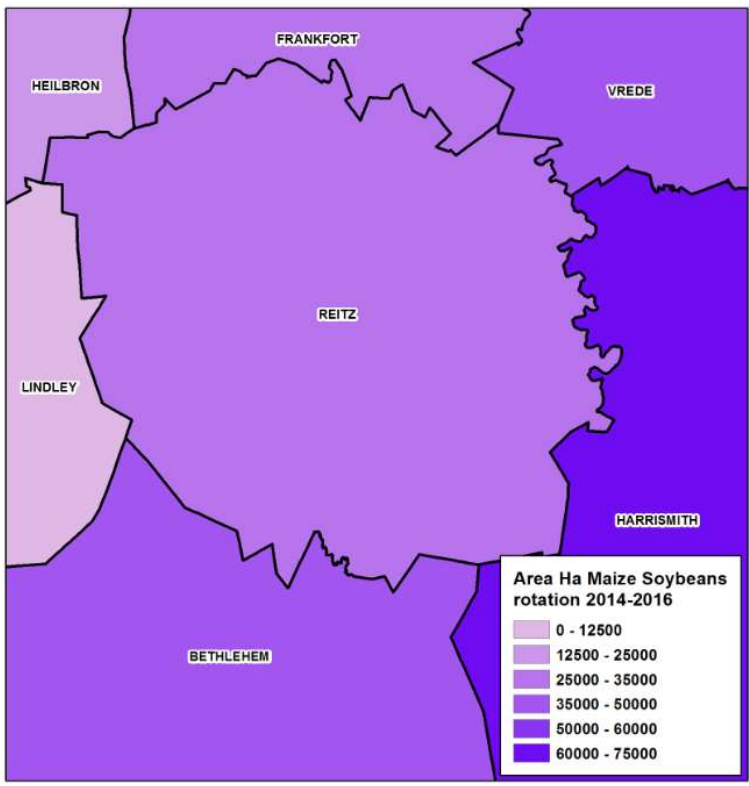

Figure 24. The area Ha rotated between maize and soybeans for the Reitz and surrounding districts between 2014 and 2016

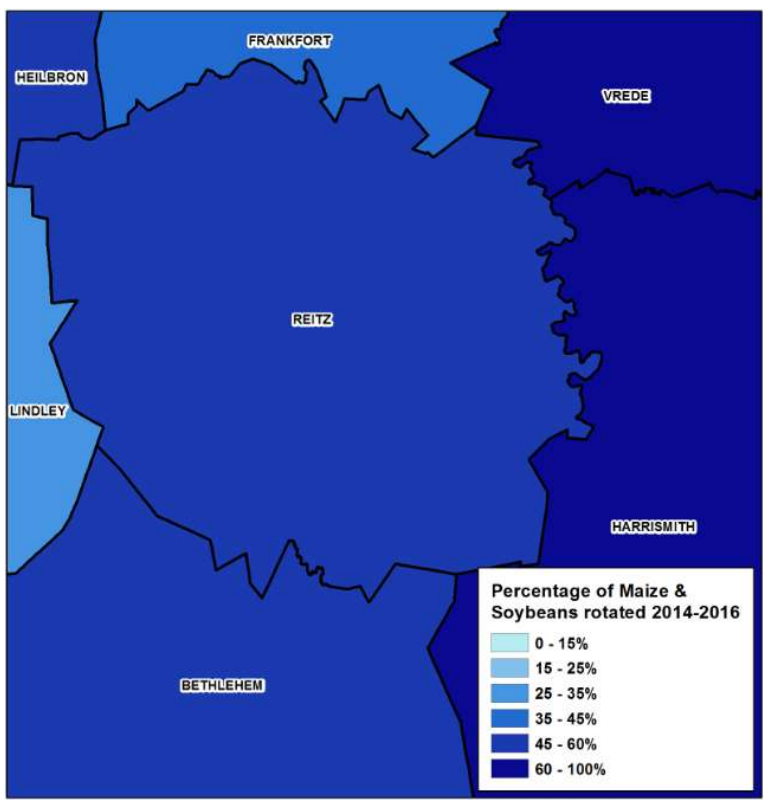

Figure 25. The percentage of area of maize and soybeans rotated for the Reitz and surrounding districts between 2014 and 2016

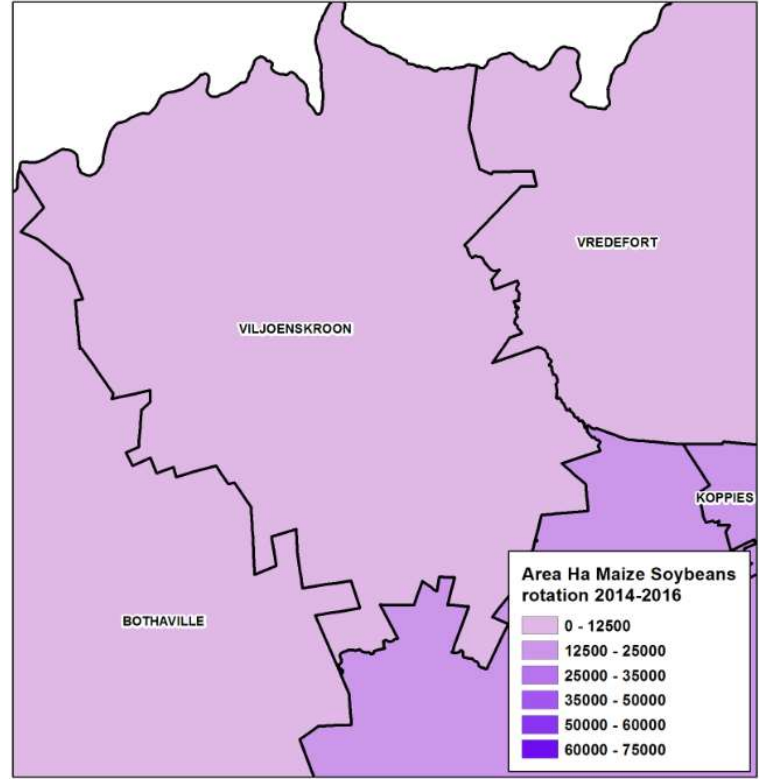

Figure 26. The area Ha rotated between maize and soybeans for the Viljoenskroon and surrounding districts between 2014 and 2016

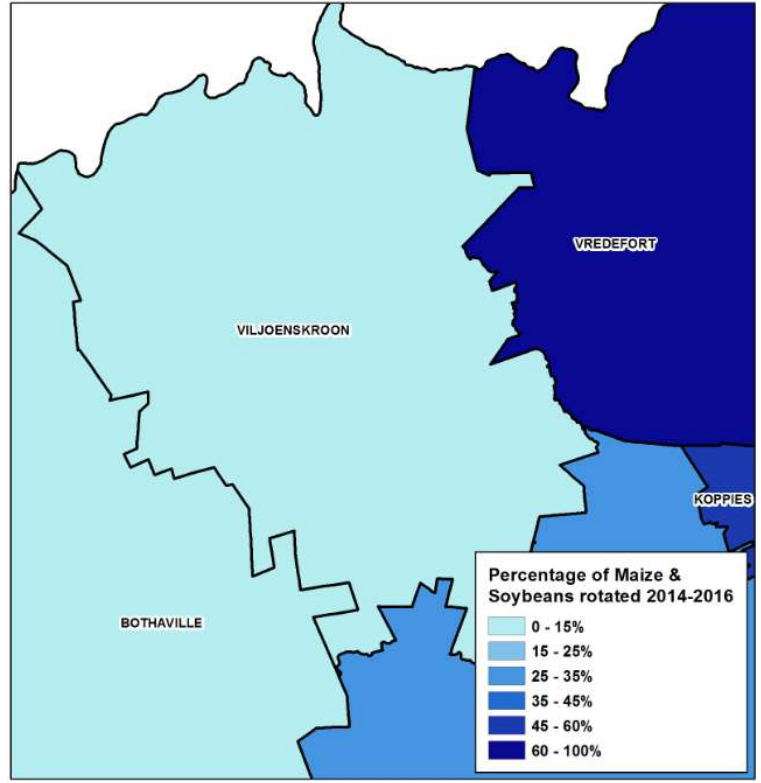

Figure 27. The percentage of area of maize and soybeans rotated for the Viljoenskroon and surrounding districts between 2014 and 2016

Comparing Reitz and Viljoenskroon in the Freestate, it is evident that they have very different crop rotation practices. Reitz is an area where a much larger area and percentage of rotation between maize and soybeans takes place compared to Viljoenskroon. However, Viljoenskroon is a very different district as far as preferred crops are concerned. For the Viljoenskroon district there was a maize area cultivated of over $80000 \mathrm{Ha}$ in 2014 and 2015 but only slightly above $50000 \mathrm{Ha}$ for 2016 due to the drought. Sunflower showed more than 9000 Ha area cultivated in 2016, up from just above $3000 \mathrm{Ha}$ in 2015. This was possibly an effort from farmers to curb financial losses 
during the drought year. Soybeans were only slightly above 3000 Ha in 2014 and 2015 and only about 350 Ha in 2016. Therefore, the recorded rotation practices are not only influenced by the preferred crops for the region but also by climatic effects which determines how much of a specific crop was cultivated. All of this information provides a broad description of crop preferences and farm management practices as far as crop rotation is concerned. The 4 districts of Bethal, Middelburg, Reitz and Viljoenskroon are compared in terms of cultivation of maize and soybeans in Table 1 below.

\begin{tabular}{|l|l|l|l|l|}
\hline & Bethal & $\begin{array}{l}\text { Middel- } \\
\text { burg }\end{array}$ & Reitz & $\begin{array}{l}\text { Viljoens- } \\
\text { kroon* }\end{array}$ \\
\hline $\begin{array}{l}\% \text { maize } \\
2014\end{array}$ & $74.9 \%$ & $82.0 \%$ & $63.9 \%$ & $83.1 \%$ \\
\hline $\begin{array}{l}\% \text { maize } \\
2015\end{array}$ & $62.1 \%$ & $72.4 \%$ & $62.5 \%$ & $83.7 \%$ \\
\hline $\begin{array}{l}\% \text { maize } \\
2016\end{array}$ & $61.2 \%$ & $79.2 \%$ & $69.5 \%$ & $70.8 \%$ \\
\hline $\begin{array}{l}\% \text { soy } \\
2014\end{array}$ & $24.7 \%$ & $17.8 \%$ & $19.9 \%$ & $3.2 \%$ \\
\hline $\begin{array}{l}\% \text { soy } \\
2015\end{array}$ & $36.7 \%$ & $25.5 \%$ & $31.3 \%$ & $3.2 \%$ \\
\hline $\begin{array}{l}\% \text { soy } \\
2016\end{array}$ & $38.7 \%$ & $20.6 \%$ & $21.5 \%$ & $0.4 \%$ \\
\hline $\begin{array}{l}\% \text { rotated } \\
2014- \\
2016\end{array}$ & $66.9 \%$ & $45.9 \%$ & $56.6 \%$ & $10.13 \%$ \\
\hline *Note Viljoenskroon experienced severe drought in 2016 \\
\hline
\end{tabular}

Table 1. The percentage of cultivation of maize and soybeans per year and percentage area that were rotated between maize and soybeans for 4 districts

From the table it is clear that Bethal has a dominant maize and soybean crop preference and also a large amount of rotation between these crops. Middelburg and Viljoenskroon has a preference for maize but with Middelburg also having a large component of soybeans and very little other crops. In Middelburg a much larger percentage area of rotation takes place between maize and soybeans than in Viljoenskroon. The climatic and soil differences between these two areas could be a contributing factor to this difference. However, sunflower and maize rotation has not been calculated and reported for Viljoenskroon, and could also play a role in the amount of crop rotation that commonly takes place. Reitz has a smaller component of maize than Middelburg, but with a similar component of soybeans and slightly more crop rotation between those 2 crops than Middelburg. This could be an indication that many fields in the Middelburg region were cultivated with maize each year during this period and did not undergo rotation.

\section{Irrigation Analysis}

The cultivated area in the field boundary vector database which are irrigated by a centre pivot were analysed and the results summarised by district for the Freestate province. Centre pivot irrigation plays a very important part in agriculture in South Africa. Centre pivot irrigated fields gather much of their water needs from sources other than rain and are therefore less prone to seasonal and climatic variations of water availability. However, centre pivots represent new challenges to surface and ground water management because the water is pumped from these water resources. South Africa is a water scarce country and water resources have to be managed carefully between different water users.

Figure 28 below is an example of Sentinel 2A satellite data of an area next to the Orange river on the south western border of the Freestate. The pivot field boundaries are overlaid over the image.

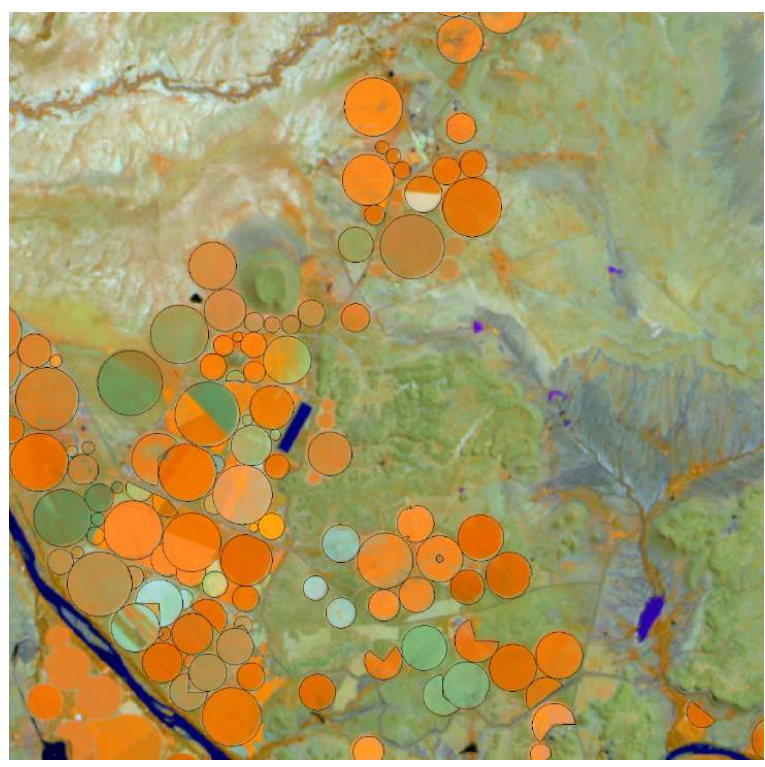

Figure 28. Sentinel 2A image next to the Orange river with pivot field boundaries overlaid

The data aggregation and analysis of pivot irrigation resulted in several methods of reporting the results at the district level. One initial calculation that was performed was the percentage of area (in Ha) of pivot irrigation of the total area of fields (both pivot and non-pivot cultivated fields), which were done per district. The results for the years 2010 and 2014 are shown in Figures $29 \& 30$ below.

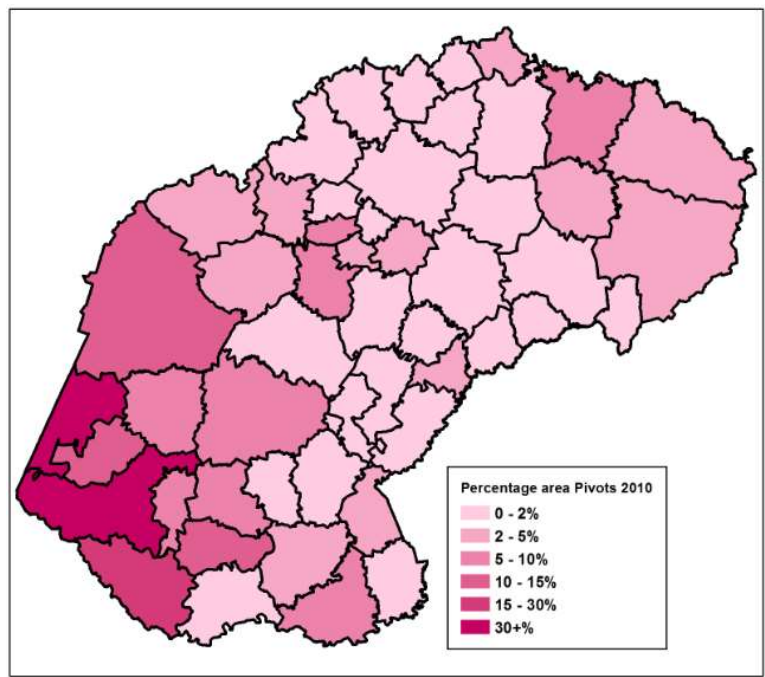

Figure 29. The percentage of all cultivated fields that are pivot irrigated per district for Freestate in 2010 


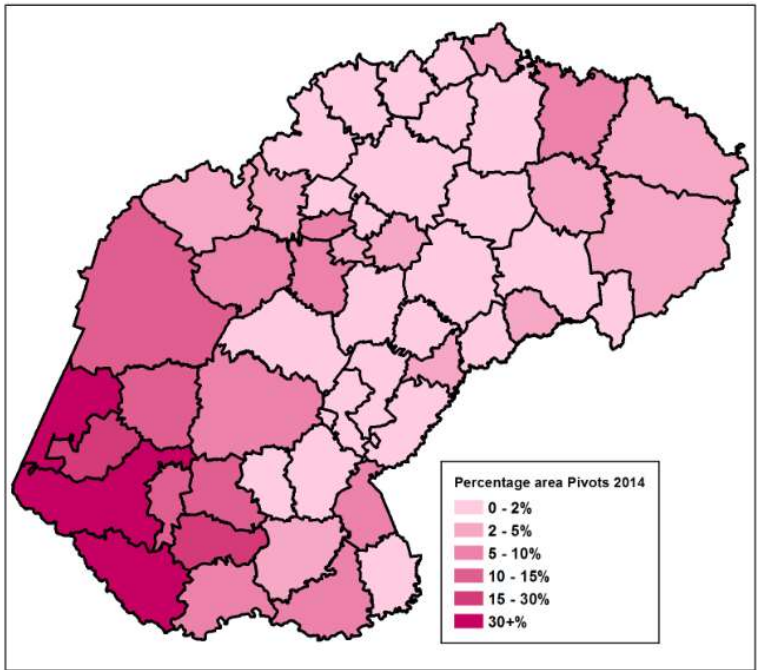

Figure 30. The percentage of all cultivated fields that are pivot irrigated per district for Freestate in 2014

From the figures above one can see that there was a slight increase of the percentage in area under pivot irrigation of all fields between 2010 and 2014 in certain districts in the western part of the province. This indicates an increasing preference for this method of crop production in those regions. The western regions of the Freestate are drier climatically, but having the significant Orange river flowing on the south western border which plays a vital role in agriculture in the region. The increase in $\mathrm{Ha}$ area of pivot irrigation for each district was calculated and displayed in Figure 31.

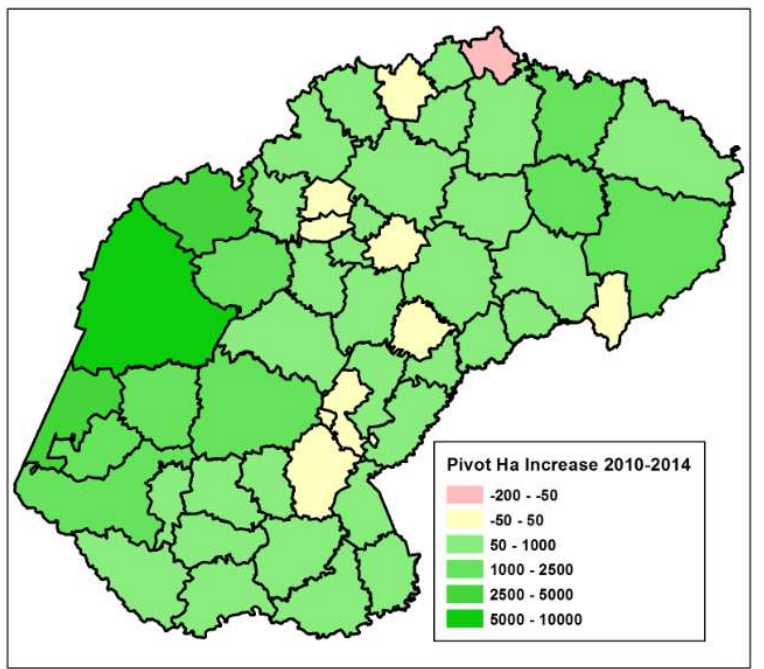

Figure 31. Increase in area Ha under pivot irrigation between 2010 and 2014 per district in the Freestate

One can see that most districts had a significant increase in the area under pivot irrigation with only one district showing a significant (but not very large) decrease of pivots between 2010 and 2014. When one views the increase or decrease of the types of crops under pivot irrigation between time periods, an interesting picture emerges. Because of the more reliable and constant water supply of pivot irrigation, many farmers can plant both a winter crop (mostly wheat) and a summer crop on the same pivot field in one year. The dynamics and choices of the types of crops cultivated under irrigation and whether a double crop or single crop per year was cultivated are displayed in the following maps (Figures 32-37). The maps represent an increase or decrease of the area under pivot irrigation for different crop types or double crop types between 2010 and 2014 .

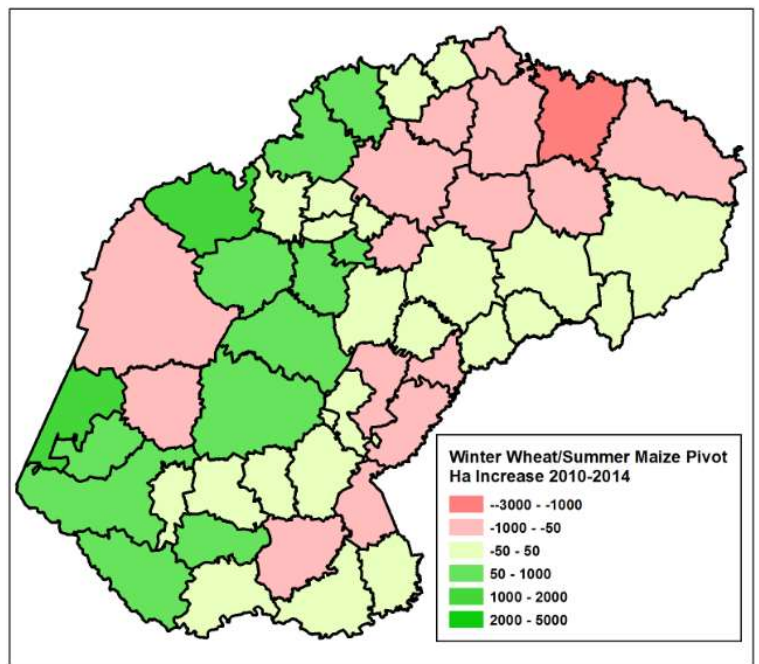

Figure 32. Double crop of wheat in winter and maize in summer area increase or decrease under pivot irrigation per district between 2010 and 2014

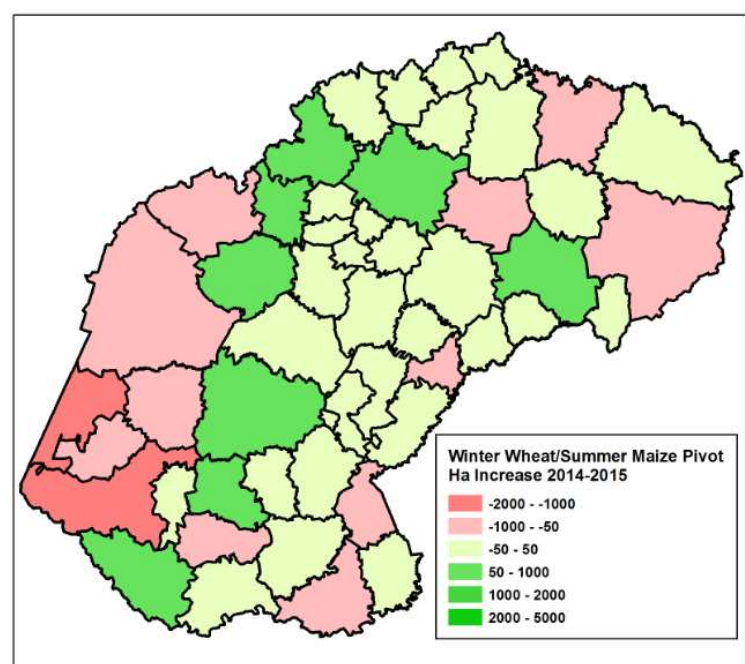

Figure 33. Double crop of wheat in winter and maize in summer area increase or decrease under pivot irrigation per district between 2014 and 2015 


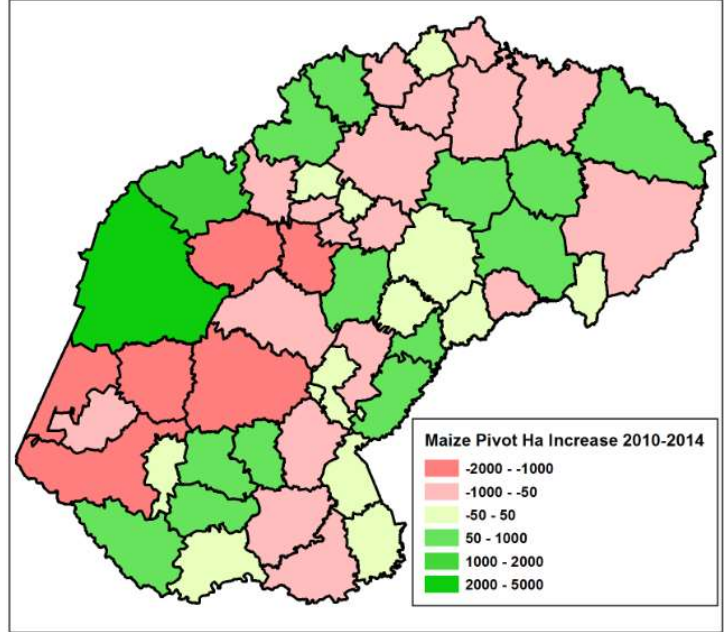

Figure 34. Maize in summer only under pivot irrigation increase or decrease per district between 2010 and 2014

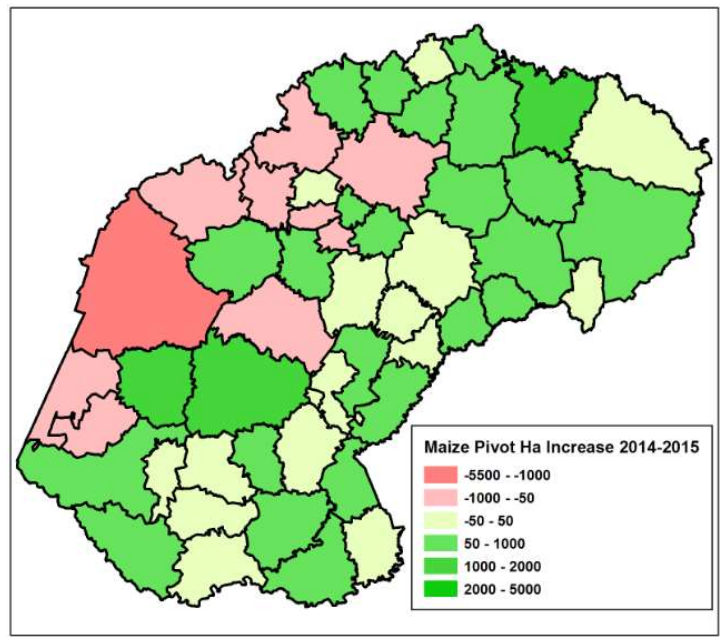

Figure 35. Maize in summer only under pivot irrigation increase or decrease per district between 2014 and 2015

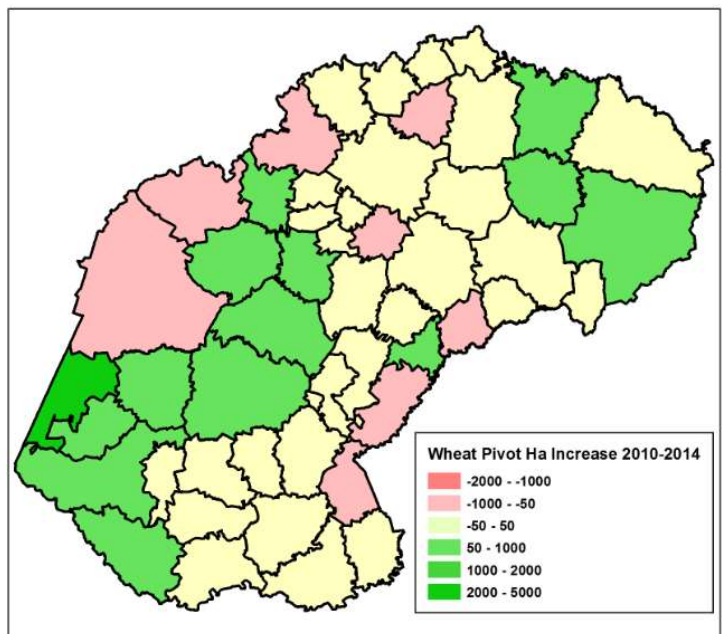

Figure 36. Wheat in winter only under pivot irrigation increase or decrease per district between 2010 and 2014

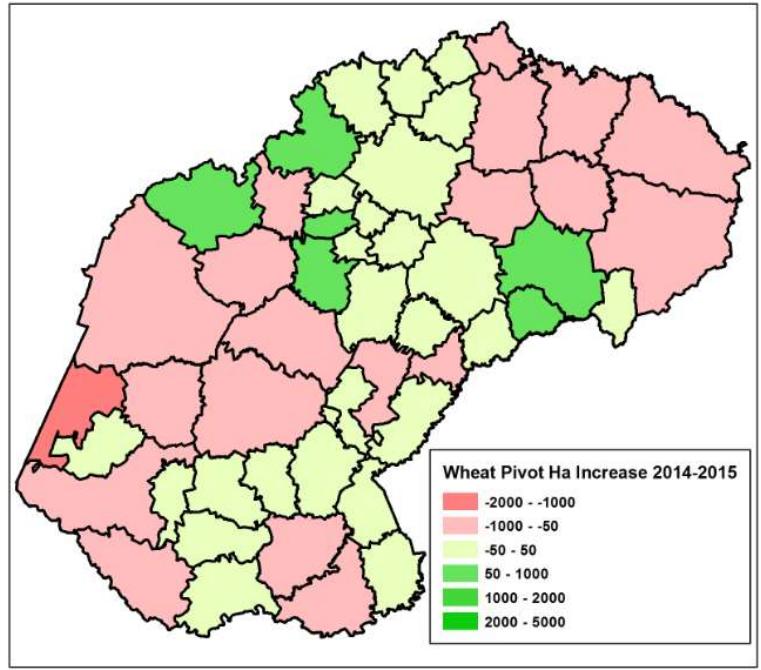

Figure 37. Wheat in winter only under pivot irrigation increase or decrease per district between 2014 and 2015

From these maps it is clear that the choices made for the type of crops cultivated per year and the decision on double cropping or a single crop for a year were a very dynamic process. The amount of annual and consecutive crop data is still too limited to determine a definite pattern.

Some of the tabular information attributes for the district of Fauresmith is inserted into Table 2 below. Examining the information in the table is another method of gaining possible insights into the farming decisions and practices of farmers in an area over time. Fauresmith is situated on the semi-arid south western border of the Freestate. The Orange River forming the south western border of the Freestate province is a critical source for irrigation agriculture in the region and many centre pivots are found close to the river. The table below contains the area in hectares (Ha) of pivot irrigation fields for different crop types. The percentage of the crop fields which had both a winter and summer crop (double crop) in the period were calculated from all crops present in the Table 2 .

\begin{tabular}{|l|c|c|c|}
\hline YEAR & 2010 & 2014 & 2015 \\
\hline $\begin{array}{l}\text { Maize } \\
\text { Ha }\end{array}$ & 3068 & 1981 & 2125 \\
\hline $\begin{array}{l}\text { Wheat } \\
\text { Ha }\end{array}$ & 481 & 1175 & 824 \\
\hline $\begin{array}{l}\text { Wheat/Maize } \\
\text { Ha }\end{array}$ & 6224 & 7003 & 5586 \\
\hline $\begin{array}{l}\text { Soybeans } \\
\text { Ha }\end{array}$ & 195 & 1199 & 40 \\
\hline $\begin{array}{l}\text { Wheat/Soy } \\
\text { Ha }\end{array}$ & 0 & 60 & 755 \\
\hline $\begin{array}{l}\text { Sunflower } \\
\text { Ha }\end{array}$ & 45 & 91 & 849 \\
\hline $\begin{array}{l}\text { Double crop } \\
\%\end{array}$ & $62 \%$ & $61 \%$ & $62 \%$ \\
\hline
\end{tabular}

Table 2. Fauresmith pivot irrigated field information for 2010, 2014 and 2015

Note that not all crop types are represented in the table. There are also significant amounts of groundnuts and lucern (alfalfa) cultivated under pivot irrigation in this area. Some pivots are also left fallow in some years and some pivots with grazing pasture 
are also present in Fauresmith. These other crops and uses were not included in the analysis. From Table 2 interesting information can be gathered, but no clear patterns other than the percentage of crops cultivated on a double cropping system of wheat in the winter followed by a summer crop (maize or soybeans) remained constant. More regular annual data could provide more insights. Double cropping of wheat and soybeans has increased each year under investigation, as well as the amount of sunflower cultivated. The year 2015 showed a large increase in both these crop choices. It is also interesting to note that double cropping is preferred over only having wheat or only maize on a pivot field in one year.

\section{Conclusion}

From the analysis above it is clear that there exists great potential in utilizing the historic classified crop type datasets in gaining knowledge from the data on farming practices and decisions. These practices and decisions can be examined in a spatially located fashion per district and the information can be represented in a quantified manner. The potential for generating important information for officials and decision makers in agribusiness certainly exists, especially if the new annual information can be added into the analysis system quickly. The improvement of data processing and classification methods, system developments and computing power makes this increasingly achievable. The increase of cost effective and reliable satellite imagery in recent years such as the Landsat 8 system, the Sentinel $2 \mathrm{~A}$ and more recently $2 \mathrm{~B}$ satellites also offers an increasing probability of achieving good quality cloud free data over the range of the growing season. This improved temporal data range is critical in accurate and effective classification of crop types at this scale. The future is promising for a imagery role player such as GeoTerraImage to offer valuable data analytics translating into useful information for agricultural decision makers and businesses.

\section{REFERENCES}

Boryan, C. et al, 2017. Developing crop specific area frame stratifications based on geospatial crop frequency and cultivation layers. Journal of Integrative Agriculture, 16(2), pp. 312-323.

DAFF 2015, Crop Estimates Committee report 29 September 2015. http://www.sagis.org.za/page536.html

DAFF 2016, Crop Estimates Committee report 27 September 2016. http://www.sagis.org.za/cec_reports_2016.html 